\title{
Investigation of the differences between the medical personnel's and general population's view on the doctor-patient relationship in China by a cross-sectional survey
}

Tianqing Sang ${ }^{1 \dagger}$, Hongli Zhou ${ }^{2+}$, Muhan $\mathrm{Li}^{1}$, Wenting $\mathrm{Li}^{1}$, Haibo Shi ${ }^{3}$, Haibin Chen ${ }^{4}$ and Hongguang Zhou ${ }^{1,5^{*}}$ (i)

\begin{abstract}
Background: Due to economic development and an increase in the aging population, the demand for medical resources is increasing. A good doctor-patient relationship (DPR) can optimize patients' medical experience and improve treatment efficiency. The DPR, however, is currently in crisis in China. To explore ways to improve DPR, this study assessed the views on the status of the DPR, medical services, and the general situation of medical work among medical personnel (MP) and the general population (GP).

Methods: This cross-sectional study, conducted between December 2019 and March 2020, targeted the MP and the GP in Nanjing City, Jiangsu Province, and Zhengzhou City, Henan Province. A total of 154 MP and 329 GP answered a self-administered questionnaire through Questionnaire Star and WeChat apps. Wilcoxon's Sign Rank Test, Chi-square test, and frequency distributions and percentages were used to process the data.

Results: Only $11.04 \%$ of the MP and $14.89 \%$ of the GP believed that the current DPR was harmonious. Moreover, $54.55 \%$ of the MP and $71.12 \%$ of the GP believed that the medical industry was a service industry. While $14.29 \%$ of the MP and $64.44 \%$ of the GP thought medical staff earned high salaries, $19.48 \%$ of the MP and $47.11 \%$ of the GP wanted their children to be in the medical industry. The recognition of the current status of the DPR did not affect the GP's preference for their children's practice $(p<0.05)$. Most MPs hoped to improve salaries $(40.26 \%)$, followed by safety (17.53\%) and social status (12.99\%); only $8.44 \%$ of the MP wanted to improve the DPR.

(Continued on next page)
\end{abstract}

\footnotetext{
* Correspondence: 260105@njucm.edu.cn

${ }^{\dagger}$ Tianqing Sang and Hongli Zhou contributed equally to this work.

'Institute of Oncology, The First Clinical Medical College, Nanjing University of Chinese Medicine, Nanjing 210046, Jiangsu Province, China

${ }^{5}$ Department of Oncology, Affiliated Hospital of Nanjing University of Chinese Medicine, Nanjing 210029, Jiangsu Province, China

Full list of author information is available at the end of the article
}

C C The Author(s). 2020 Open Access This article is licensed under a Creative Commons Attribution 4.0 International License, which permits use, sharing, adaptation, distribution and reproduction in any medium or format, as long as you give appropriate credit to the original author(s) and the source, provide a link to the Creative Commons licence, and indicate if changes were made. The images or other third party material in this article are included in the article's Creative Commons licence, unless indicated otherwise in a credit line to the material. If material is not included in the article's Creative Commons licence and your intended use is not permitted by statutory regulation or exceeds the permitted use, you will need to obtain permission directly from the copyright holder. To view a copy of this licence, visit http://creativecommons.org/licenses/by/4.0/ The Creative Commons Public Domain Dedication waiver (http://creativecommons.org/publicdomain/zero/1.0/) applies to the data made available in this article, unless otherwise stated in a credit line to the data. 
(Continued from previous page)

Conclusion: The MP's and GP's views on the current status of DPR, the importance of medical service attitudes, and the general sense of the medical industry were similar. However, there was a significant difference in the perception of the nature of medical services and the income of the people employed in the medical industry between the two groups. Balancing the expectations of patients in the medical industry and increasing public awareness of the actual situation in the medical industry may be a feasible way to improve the DPR.

Keywords: Doctor-patient relationship (DPR), Medical dispute, Patient satisfaction, People's republic of China,

\section{Background}

The doctor-patient relationship (DPR) is the interactive relationship in the medical service activities between doctors and patients, as well as between the individuals and social groups that are closely related to the interests of both parties. Globally, due to the commercialization and privatization of the medical industry, the DPR has undergone tremendous changes over the past few decades [1]. DPR has changed from being doctor-centric to patient-centric. This patient-centric model of DPR reduces physician dominance, advocates greater patient control, and encourages more mutual participation. This has become the predominant model in clinical practice today [2].

In recent years, the demand for better health care in the third-world countries has gradually increased, and an expanding aging population has become a global health care problem due to limited medical resources [3]. The People's Republic of China is a developing country with a population of about 1.4 billion. In China, medical resources are dominated by public ownership. To offer better health care, since the 2010s, the Chinese government has adopted a series of effective reforms that include expansion of the social health insurance, reform of the public hospitals, and strengthening of primary care. These reforms have succeeded in reducing mortality, increasing life expectancy, and providing better primary health care $[4,5]$. However, as the aging population continues to increase, China's limited medical resources will face huge challenges in the future [6].

From a sociological perspective, DRP depends on the ethics of both doctors and patients. From a psychological perspective, "communication behavior patterns", "psychic distance", "emotional quotient", "conflict between pain relief and truth-telling", and "body language" affect DRP $[2,7]$. Studies showed that DRP is seen as the behavior and attitude of the doctor towards the patient, and the perception of the patient concerning the caring shown by the doctor [8]. A harmonious DPR can A good DPR can optimize patients' medical experience and improve treatment efficiency, outcomes that are important to both the doctors and patients. While the DPR has been the focus of public opinion, Workplace violence experienced by doctors has been documented both in developed and developing countries, which is also in crisis in China [9]. Reports show over the past few years, violent behaviors such as violent abuse, riots, assaults and hospital protests against medical professionals have surged in China. Chinese medical professionals are being injured, disabled, or even killed by patients or their family members $[10,11]$. Despite the heavy workload of Chinese medical professionals, they have been disabled, injured, or even killed by patients or their families [12]. Although there are many reports and studies on DPR in China [13-15], there are only a few in-depth and comprehensive studies have focused on improving the DPR by investigating medical personnel (MP) and the general population (GP) simultaneously. This study focused on both doctors and patients, compared the differences in perception between MP and GP on the status of DPR, medical services, and the general situation of medical work, in order to explore a feasible way to improve the DPR.

\section{Methods}

\section{Study design}

This was a cross-sectional study, and data were collected using questionnaires.

\section{Population and data collection procedure}

The scope of this research survey was limited to Nanjing City, Jiangsu Province, and Zhengzhou City, Henan Province. A total of $154 \mathrm{MP}$ and 329 GP respondents participated in the study. Data were collected using a self-administered online questionnaire, distributed through Questionnaire Star and WeChat apps. While participation in the study was voluntary, the participants received monetary compensation (After completing the questionnaire and submitting it successfully, each respondent will receive $10 \mathrm{RMB}$.). All participants signed the informed consent form attached to the questionnaire prior to answering any question. The participants had $15 \mathrm{~min}$ to answer the questionnaire.

\section{Questionnaire}

We define DPR through three levels of "harmony", "Tense" and "Normal", "Harmonious" DPR mainly means that both the doctor and the patient can always 
Table 1 Background characteristics of MPs and GPs

\begin{tabular}{llll}
\hline Group & MPs (\%) & GPs (\%) & P \\
\hline Gender & & & 0.71 \\
Male & $56(36.36)$ & $127(38.60)$ & \\
Female & $98(63.64)$ & $202(61.40)$ & \\
Age & & & 0.21 \\
$\leq 25$ & $34(22.08)$ & $28(8.51)$ & \\
$26-35$ & $83(53.90)$ & $80(24.32)$ & \\
$36-45$ & $13(8.44)$ & $77(23.40)$ & \\
46-55 & $22(14.29)$ & $86(26.14)$ & \\
$\quad \geq 56$ & $2(1.30)$ & $58(17.63)$ & \\
MPs' Education & & & \\
Technical secondary school/college & $10(6.49)$ & & \\
Undergraduate & $57(37.01)$ & & \\
Master's degree & $78(50.65)$ & & \\
PhD and above & $9(5.84)$ & & \\
GPs' Education & & & \\
Elementary school and below & & $5(1.52)$ & \\
Junior and high school & & $68(20.67)$ & \\
Technical secondary school/college & & $88(26.75)$ & \\
Undergraduate & & & \\
Postgraduate and above & & & \\
Place of residence & & & \\
Village/township/town & & & \\
County-level cities/prefecture-level cities & $53(34.42)$ & $90(27.36)$ & \\
Provincial capital cities/Municipalities & $80(51.95)$ & $185(56.23)$ & \\
\hline & & & \\
\hline
\end{tabular}

complete the treatment process in a relaxed and friendly atmosphere. "Tense" DPR mainly refers to the fact that both the doctor and the patient cannot trust each other, fail to complete the medical treatment process smoothly, and cause medical disputes and even violent injuries to the doctor. "Average" refers to the state of DPR between harmony and tension. Although both doctors and patients cannot fully trust each other, there are not always medical disputes and violent incidents.

Self-administered questionnaires covering three aspects were answered by the participating MP and GP respondents. The first part of the questionnaire used by the MP included items on sociodemographic factors: Gender, Age, Job title (Primary, Intermediate, Deputy Senior, Advanced), Department (Internal Medicine, Surgical, Obstetrics and Gynecology, Pediatrics, Emergency Department, Medical Technology Department, and Other Auxiliary Departments), Years on the Job, Hospital Type (Traditional Chinese Medicine, Modern medicine and Integrated Chinese and Western Medicine), Hospital level (Community, Level 2, Level 3, Other Medical Institutions), Practice Category (Nursing, Traditional Chinese Medicine Physician, Modern Medicine Physician, Integrated Chinese, and Western Medicine Physician), Education (Technical Secondary School/College, Undergraduate, Master's degree, Ph.D. and Above), and Place of Residence (Village/Township/Town, Countylevel Cities/Prefecture-level Cities, Provincial Capital Cities/Municipalities). The first part of the questionnaire used by GP included items on sociodemographic factors: Gender, Age, Place of Residence (Village/Township/ Town, County-level Cities/Prefecture-level Cities, Provincial Capital cities/Municipalities), Education (Elementary School and Below, Junior and High school, Technical Secondary School/College, Undergraduate, Postgraduate and Above), Job type (Institution/Civil Service, Private Enterprise Employees, Self-employed, Unemployed and Student), and Previous Hospitalization (Yes or No).

In the second part of the questionnaire, the participants were asked whether the medical industry belonged

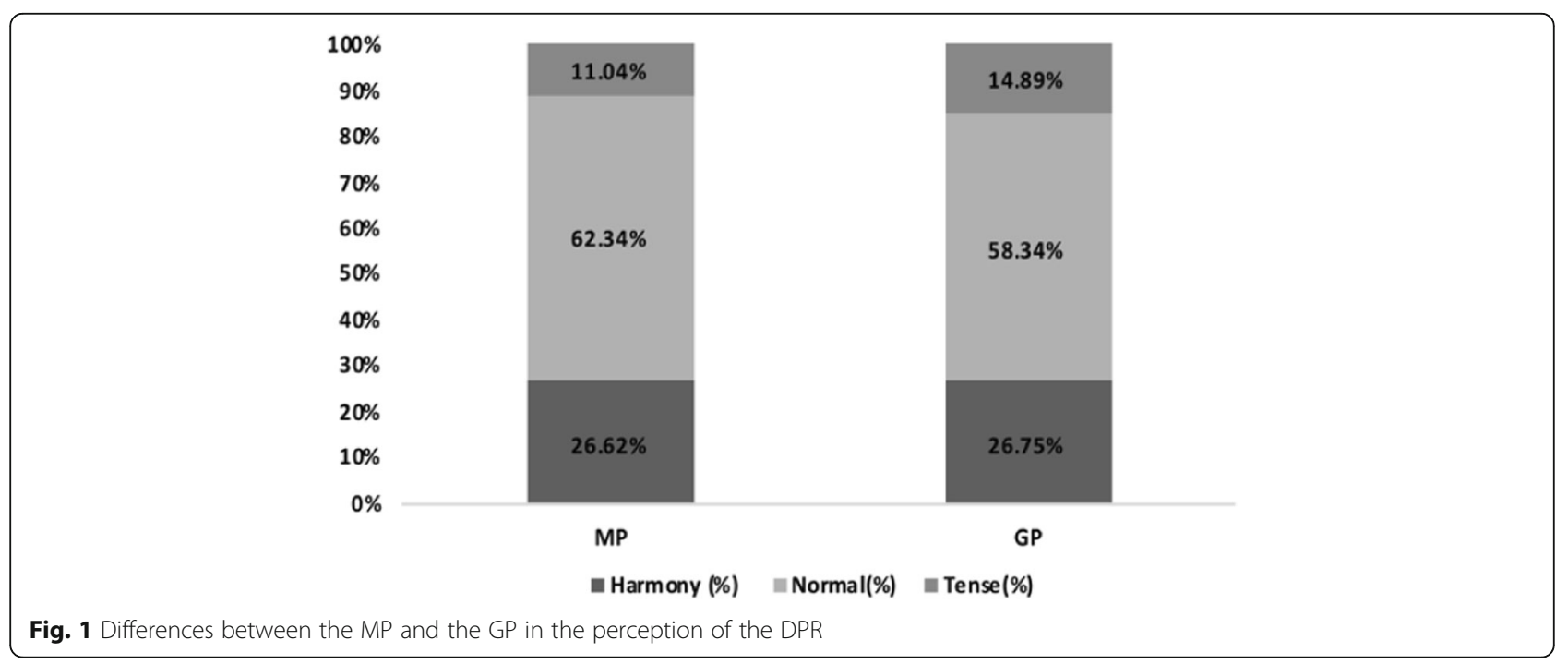


Table 2 General population data of 154 MPs and the difference in the perception of the status of the doctor-patient relationship among groups

\begin{tabular}{|c|c|c|c|c|c|}
\hline Group & $\begin{array}{l}\text { Harmony } \\
(\%)\end{array}$ & Normal(\%) & Tense(\%) & $x^{2}$ & $\mathbf{P}$ \\
\hline Gender & & & & 0.01 & 0.995 \\
\hline Male & 6(35.29) & $35(36.46)$ & 15(36.59) & & \\
\hline Female & $11(64.71)$ & $61(63.54)$ & $26(63.41)$ & & \\
\hline Age & & & & 3.97 & 0.86 \\
\hline$\leq 25$ & $4(23.53)$ & $21(21.88)$ & $9(21.95)$ & & \\
\hline $26-35$ & 7(41.18) & $52(54.17)$ & $24(58.54)$ & & \\
\hline $36-45$ & 2(11.76) & $7(7.29)$ & $4(9.76)$ & & \\
\hline $46-55$ & $4(23.53)$ & $14(14.58)$ & $4(9.76)$ & & \\
\hline$\geq 56$ & $0(0.00)$ & $2(2.08)$ & $0(0.00)$ & & \\
\hline Department & & & & 5.788 & 0.926 \\
\hline Internal Medicine & 10(58.82) & $46(47.92)$ & $22(53.66)$ & & \\
\hline Surgical & $1(5.88)$ & $20(20.83)$ & $9(21.95)$ & & \\
\hline $\begin{array}{l}\text { Obstetrics and } \\
\text { Gynecology }\end{array}$ & $1(5.88)$ & $3(3.13)$ & $2(4.88)$ & & \\
\hline Pediatrics & $1(5.88)$ & $5(5.21)$ & $2(4.88)$ & & \\
\hline $\begin{array}{l}\text { Emergency } \\
\text { department }\end{array}$ & $0(0.00)$ & $2(2.08)$ & $0(0.00)$ & & \\
\hline $\begin{array}{l}\text { Medical } \\
\text { Technology } \\
\text { department }\end{array}$ & $0(0.00)$ & $4(4.17)$ & $1(2.44)$ & & \\
\hline $\begin{array}{l}\text { Other auxiliary } \\
\text { departments }\end{array}$ & $4(23.53)$ & $16(16.67)$ & $5(12.20)$ & & \\
\hline Years on the Job & & & & 8.645 & 0.373 \\
\hline$\leq 5$ & 10(58.82) & $69(71.88)$ & $31(75.61)$ & & \\
\hline $6-10$ & $2(11.76)$ & $6(6.25)$ & $2(4.88)$ & & \\
\hline $11-20$ & $1(5.88)$ & $2(2.08)$ & $4(9.76)$ & & \\
\hline $21-30$ & $4(23.53)$ & 16(16.67) & $4(9.76)$ & & \\
\hline$\geq 31$ & $0(0.00)$ & $3(3.13)$ & $0(0.00)$ & & \\
\hline Job title & & & & 11.014 & 0.088 \\
\hline Primary & 10(58.82) & 71(73.96) & $30(73.17)$ & & \\
\hline Intermediate & $5(29.41)$ & 13(13.54) & $5(12.20)$ & & \\
\hline Deputy Senior & $0(0.00)$ & $6(6.25)$ & $6(14.63)$ & & \\
\hline Advanced & $2(11.76)$ & $6(6.25)$ & $0(0.00)$ & & \\
\hline Hospital type & & & & 1.715 & 0.788 \\
\hline TCM & 12(70.59) & $59(61.46)$ & $24(58.54)$ & & \\
\hline $\mathrm{MM}$ & $3(17.65)$ & $20(20.83)$ & 7(17.07) & & \\
\hline ICWM & 2(11.76) & $17(17.71)$ & 10(24.39) & & \\
\hline Hospital level & & & & 3.332 & 0.766 \\
\hline Community & $2(11.76)$ & $7(7.29)$ & $2(4.88)$ & & \\
\hline Level 2 & $2(11.76)$ & $21(21.88)$ & $8(19.51)$ & & \\
\hline Level 3 & $12(70.59)$ & $56(58.33)$ & 28(68.29) & & \\
\hline Other medical institutions & $1(5.88)$ & $12(12.50)$ & $3(7.32)$ & & \\
\hline Practice category & & & & 8.032 & 0.236 \\
\hline Nursing & $0(0.00)$ & $4(4.17)$ & $2(4.88)$ & & \\
\hline
\end{tabular}


Table 2 General population data of 154 MPs and the difference in the perception of the status of the doctor-patient relationship among groups (Continued)

\begin{tabular}{|c|c|c|c|c|c|}
\hline Group & $\begin{array}{l}\text { Harmony } \\
\text { (\%) }\end{array}$ & Normal(\%) & Tense(\%) & $x^{2}$ & $\mathbf{P}$ \\
\hline TCM physician & $14(82.35)$ & 68(70.83) & $32(78.05)$ & & \\
\hline MM physician & $1(5.88)$ & $11(11.46)$ & $7(17.07)$ & & \\
\hline ICWM physician & $2(11.76)$ & 13(13.54) & $0(0.00)$ & & \\
\hline \multicolumn{6}{|l|}{ Education } \\
\hline $\begin{array}{l}\text { Technical } \\
\text { secondary } \\
\text { school/college }\end{array}$ & $0(0.00)$ & $7(7.29)$ & $3(7.32)$ & 9.707 & 0.138 \\
\hline Undergraduate & $5(29.41)$ & $41(42.71)$ & $11(26.83)$ & & \\
\hline Master's degree & $9(52.94)$ & $45(46.88)$ & $24(58.54)$ & & \\
\hline $\mathrm{PhD}$ and above & $3(17.65)$ & $3(3.13)$ & $3(7.32)$ & & \\
\hline Place of residence & & & & 3.38 & 0.496 \\
\hline $\begin{array}{l}\text { Village/township/ } \\
\text { town }\end{array}$ & $4(23.53)$ & $11(11.46)$ & $6(14.63)$ & & \\
\hline $\begin{array}{l}\text { County-level } \\
\text { cities/prefecture- } \\
\text { level cities }\end{array}$ & $3(17.65)$ & $35(36.46)$ & 15(36.59) & & \\
\hline $\begin{array}{l}\text { Provincial capital } \\
\text { cities/ } \\
\text { Municipalities }\end{array}$ & $10(58.82)$ & $50(52.08)$ & $20(48.78)$ & & \\
\hline
\end{tabular}

TCM Traditional Chinese Medicine, MM Modern Medicine, ICWM Integrated Chinese and Western Medicine Physician

to the service industry and whether the service attitude of medical personnel with professional skills was important. Responses from the MP and the GP cohorts were investigated separately. And investigated GP about whether the service attitude of medical staff is appropriate compared with government staff/service staff. The third part of the questionnaire was aimed at finding the difference between the MP and GP respondents' perception of the medical industry. The MP and GP's views on the medical staff's income level and whether they wanted their children to be in the medical field were investigated as well. Finally, the MP's opinion on how to improve in routine medical work (Social Status, Salary, Safety, Work time, Night Shift Frequency, Cumbersome Hospital Assessment, Doctor-patient Relationship, Working Environment) was also investigated.

\section{Statistical analysis}

All data were incorporated into a Microsoft Excel spreadsheet. Data analyses were done using SPSS, version 22.0, and SPSSAU, version 20.0. Wilcoxon's Sign Rank Test was implemented to compare the differences in attitude scores between the two groups. Chi-square test was used for categorical data between the groups, and categorical data were summarized using frequency distributions and percentages. A value of $p<0.05$ was considered significant.

\section{Result}

\section{Characteristics of the sample}

The background characteristics of the participants are shown in Table 1. Female make up the majority of participants (MP 63.64\%, GP 61.40\%). The largest number of Participants live in Provincial capital cities/Municipalities (MP 51.95\%, GP 56.23\%). The age of the participating GPs is relatively average, while the most MPs participating in the survey are $26-35$ years old (53.90\%). In terms of education, MPs has the most Master's degree (50.65\%) and GPs has the most Undergraduate (38.30\%). A total of $41(26.62 \%)$ of the 154 MPs believed the DPR to be tense, $96(62.34 \%)$ thought it to be average, and only $17(11.04 \%)$ thought it to be harmonious. Of the 329 GP respondents, 88 (26.75\%) believed that the current DPR was tense, 192 (58.36\%) thought it was average, and $49(14.89 \%)$ thought it was harmonious. The cognitive difference of the current situation for the DPR between medical personnel and non-medical personnel is shown in Fig. 1. Among the MPs, age, gender, department, years on the job, professional title, hospital level, type of practice, education, and place of residence had no statistical significance on the evaluation of the DPR $(p>0.05)$. Among the GPs, gender, work type, education, place of residence, and prior hospital admittance had no statistical significance on the evaluation of the DPR $(p>0.05)$; the data are given in Table 2. Age, 
Table 3 General population data of 329 GPs and the differences in the perception of the status of the DPR between groups

\begin{tabular}{|c|c|c|c|c|c|}
\hline Group & Harmony (\%) & Normal(\%) & Tense(\%) & $x^{2}$ & $\mathbf{P}$ \\
\hline Gender & & & & 1.695 & 0.428 \\
\hline Male & $23(46.94)$ & $71(36.98)$ & $33(37.50)$ & & \\
\hline Female & $26(53.06)$ & $121(63.02)$ & $55(62.50)$ & & \\
\hline Age & & & & 25.26 & 0.001 \\
\hline$\leq 25$ & $0(0.00)$ & $16(8.33)$ & $12(13.64)$ & & \\
\hline $26-35$ & $4(8.16)$ & $57(29.69)$ & 19(21.59) & & \\
\hline $36-45$ & $12(24.49)$ & $44(22.92)$ & $21(23.86)$ & & \\
\hline $46-55$ & $16(32.65)$ & $47(24.48)$ & $23(26.14)$ & & \\
\hline$\geq 56$ & 17(34.69) & $28(14.58)$ & $13(14.77)$ & & \\
\hline Job type & & & & 15.394 & 0.052 \\
\hline Civil Service & $16(32.65)$ & $70(36.46)$ & $20(22.73)$ & & \\
\hline Private enterprise employees & 17(34.69) & $70(36.46)$ & $42(47.73)$ & & \\
\hline Self-employed & $6(12.24)$ & 21(10.94) & $7(7.95)$ & & \\
\hline Unemployed & $10(20.41)$ & $21(10.94)$ & 10(11.36) & & \\
\hline Student & $0(0.00)$ & $10(5.21)$ & $9(10.23)$ & & \\
\hline Education & & & & 13.57 & 0.094 \\
\hline Elementary school and below & $3(6.12)$ & $1(0.52)$ & $1(1.14)$ & & \\
\hline Junior and high school & $10(20.41)$ & $40(20.83)$ & 18(20.45) & & \\
\hline Technical secondary school/college & 16(32.65) & $45(23.44)$ & 27(30.68) & & \\
\hline Undergraduate & 17(34.69) & $80(41.67)$ & 29(32.95) & & \\
\hline Postgraduate and above & $3(6.12)$ & $26(13.54)$ & 13(14.77) & & \\
\hline Place of residence & & & & 5.188 & 0.269 \\
\hline Village/township/town & $8(16.33)$ & $32(16.67)$ & 14(15.91) & & \\
\hline County-level cities/prefecture-level cities & $9(18.37)$ & $50(26.04)$ & $31(35.23)$ & & \\
\hline Provincial capital cities/Municipalities & $32(65.31)$ & 110(57.29) & $43(48.86)$ & & \\
\hline Previous Hospitalization & & & & 4.217 & 0.121 \\
\hline Yes & 47(95.92) & 179(93.23) & 87(98.86) & & \\
\hline No & $2(4.08)$ & $13(6.77)$ & $1(1.14)$ & & \\
\hline
\end{tabular}

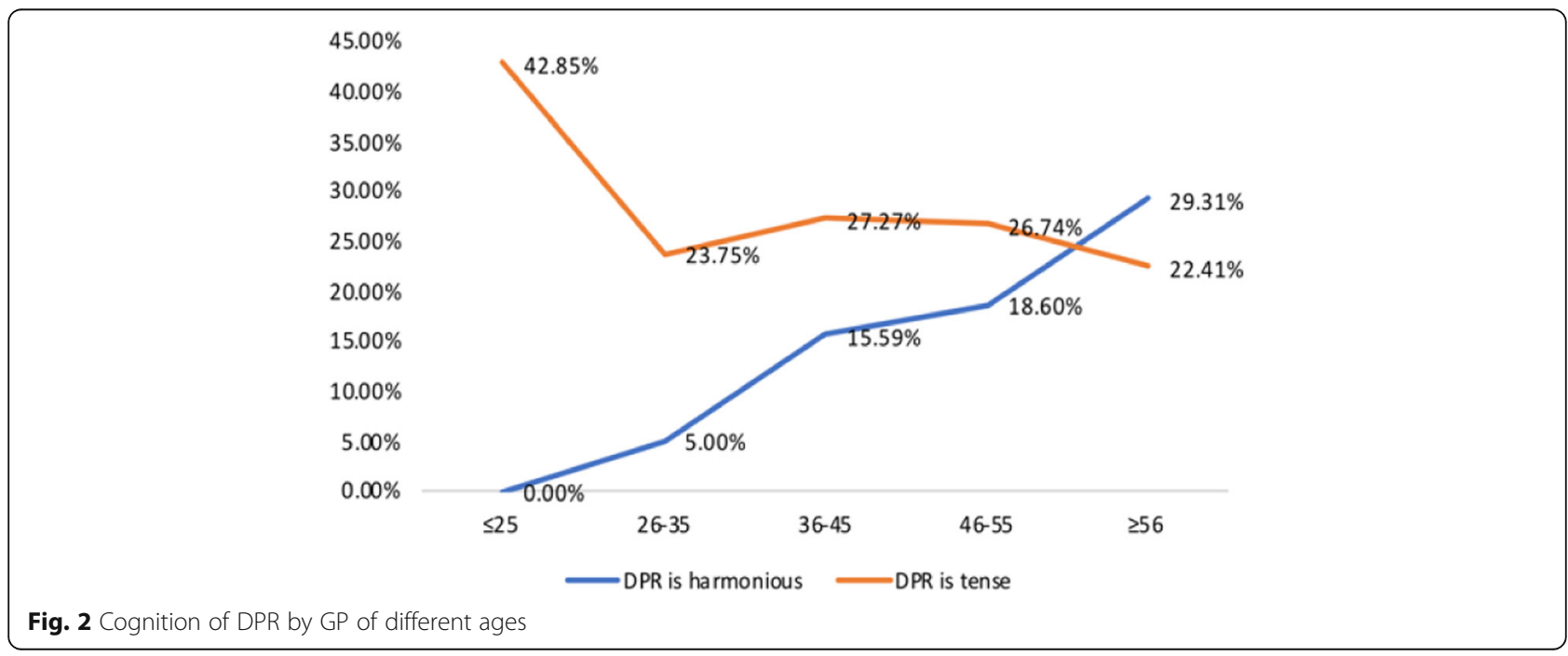




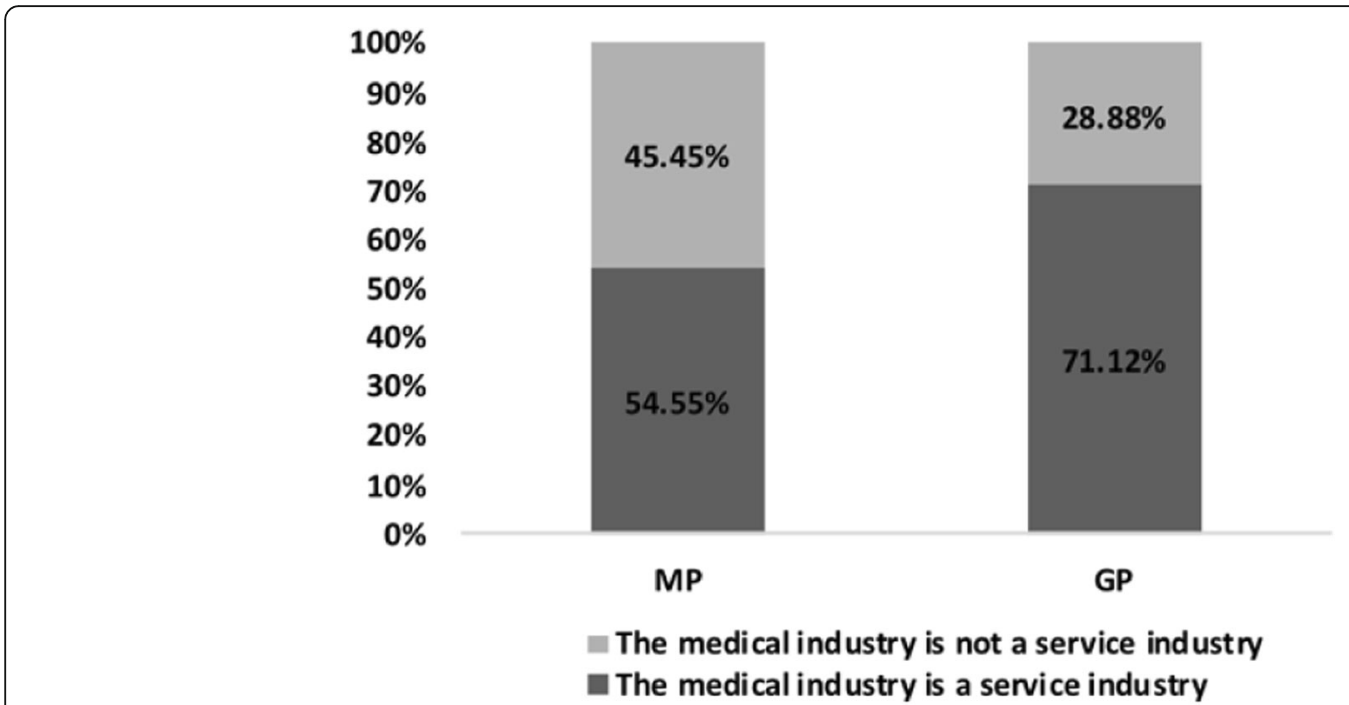

Fig. 3 Differences in perception between the MP and the GP respondents on medical services

however, was a statistically significant factor in the GPs on the evaluation of the DPR $(p=0.01)$; the data are given in Table 3. With age, GPs tended to think DPR is harmonious, as shown in Fig. 2.

\section{Differences between the MP's and the GP's perception of} medical services

A total of $84(54.55 \%)$ of the 154 MPs believed that the medical industry was a service industry, and 70 (45.45\%) thought it was not. A total of 150 (97.4\%) MPs thought that the service attitude of medical staff was as important as professional skills, and only 4 MPs (2.6\%) considered it was not. While 234 (71.12\%) of the 329 GPs thought that the medical industry was a service industry, $95(28.88 \%)$ did not. Interestingly, 315 (95.74\%) GPs thought that the attitude of medical staff is more important than professional skills and only 14 GPs $(4.26 \%)$ considered it to be unimportant. The difference between MP and GP's perception of medical services is shown in Fig. 3. Age, gender, department, years on the job, job title, hospital level, practice category, education and place of residence had no statistical significance for the MP's perception on whether the medical industry was a service industry $(p>0.05)$; the data are shown in Table 4. Gender and prior hospitalization were statistically significant factors for the GPs' perception of

Table 4 Differences in the MPs' perception of medical services

\begin{tabular}{llll}
\hline Is the medical industry a service industry? & & \\
\hline Group & & $\mathbf{X}^{\mathbf{2}}$ & $\mathbf{P}$ \\
\hline Years on the Job & $\leq 5 / 6-10 / 11-20 / 21-30 / \geq 31$ & 10.413 & 0.034 \\
Hospital type & TCM/MM/ICWM & 8.286 & 0.016 \\
\hline
\end{tabular}

whether the medical industry was a service industry. Education has statistical significance for GPs' perception of the importance of the service attitude of medical staff $(p<0.05)$; the data are given in Table 5. The GPs' perception difference in service attitudes between medical staff and government staff/service staff is shown in Fig. 4. Comparison of the service attitudes between the medical staff and the government staff shows that $45.15 \%$ of the GPs believed that the service attitude of both sectors was good in general, while $26.06 \%$ believed the service of the medical staff was better, and only $6.06 \%$ thought service attitude was bad in both sectors. A comparison of the service attitudes between the medical staff and the service staff showed that $41.25 \%$ of the GPs believed that the service attitude of the service staff was better, $17.58 \%$ thought that the medical staff was better, and only $1.52 \%$ thought both were bad.

Table 5 Differences in the GPs' perception of medical services (a) Compared with professional skills, is the service attitude of medical staff important?

\begin{tabular}{|c|c|c|c|}
\hline \multicolumn{2}{|l|}{ Group } & \multirow{2}{*}{$\begin{array}{l}X^{2} \\
6.684\end{array}$} & \multirow{2}{*}{$\begin{array}{l}\mathbf{P} \\
0.010\end{array}$} \\
\hline Gender & Male/Female & & \\
\hline $\begin{array}{l}\text { Previous } \\
\text { Hospitalization }\end{array}$ & Yes/No & 30.08 & 0.000 \\
\hline \multicolumn{4}{|c|}{ (b) Is the medical industry a service industry? } \\
\hline Group & & $x^{2}$ & $\mathbf{P}$ \\
\hline Education & $\begin{array}{l}\text { Elementary school and below, Junior } \\
\text { and high school, Technical secondary } \\
\text { school/college, Undergraduate, } \\
\text { Postgraduate and above }\end{array}$ & 20.807 & 0.000 \\
\hline
\end{tabular}




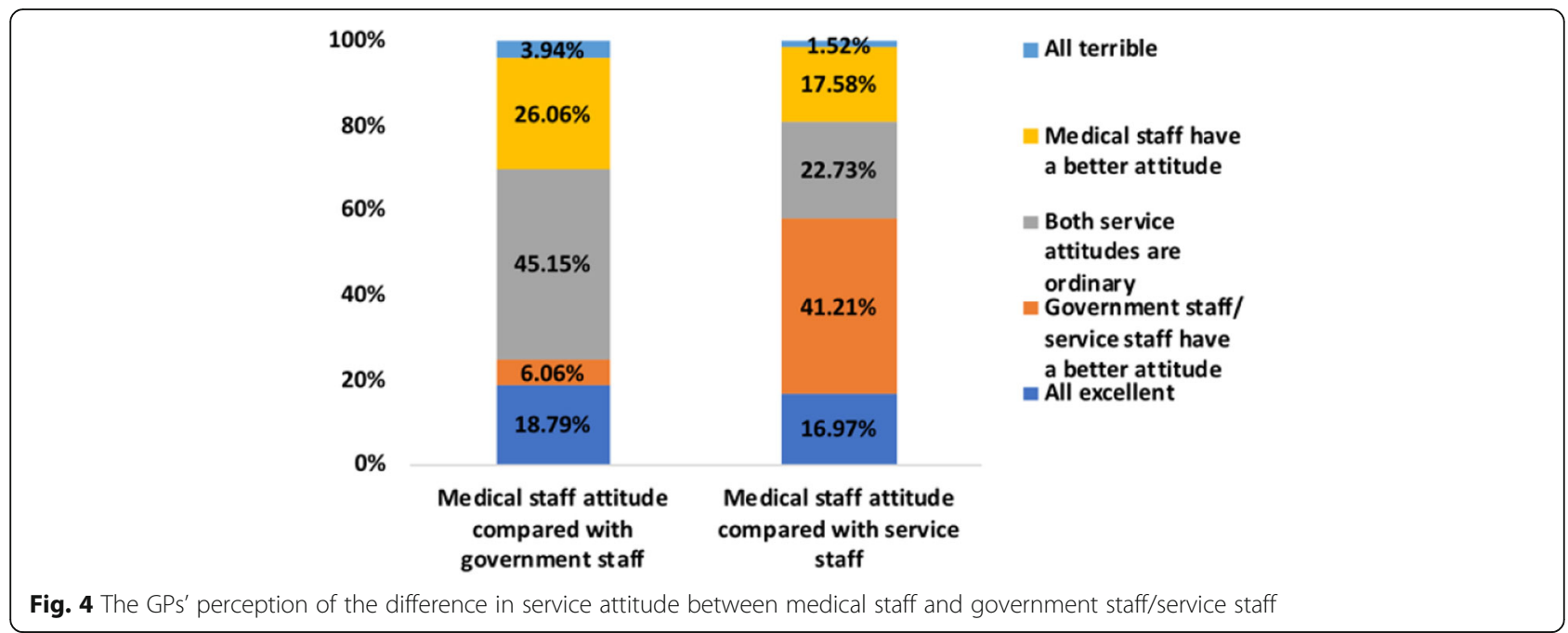

Differences in perception between the MP and the GP on the medical industry

Differences in perception between the MP and the GP on medical industry income

Of the 154 MP respondents, 132 (85.71\%) thought that medical staff did not earn high salaries, and only 22 (14.29\%) thought they did. All factors such as age, gender, department, years on the job, job title, hospital level, practice category, education, and place of residence had no statistical significance for MP's cognition of the medical staff's income level, $(P>0.05)$. Of the 329 GP respondents, 117 (35.56\%) thought that medical staff did not earn high salaries, and 212 (64.44\%) thought they did. Two factors, age and job type, have statistical significance for MP's cognition of the medical staff's income level $(P<0.05)$; the data are given in Table 6 . The difference between the MP and GP respondents' perception of the medical staff's income level is shown in Fig. 5.

\section{Differences between MP and GP respondents in choosing} whether their children are engaged in the medical industry Of the 154 MP respondents, 74 (48.05\%) did not want their children to be in the medical industry, and only 30 (19.48\%) wanted that. In contrast, 155 (47.11\%) of the 329 GP respondents wanted their children to be in the medical profession, and only $65(19.76 \%)$ did not. The difference between the two in choosing whether they

Table 6 Differences in GPs' perceptions of income from the medical industry

\begin{tabular}{llll}
\hline Group & & $\mathbf{X}^{\mathbf{2}}$ & $\mathbf{P}$ \\
\hline Age & $\leq 25 / 26-35 / 36-45 / 46-55 / \geq 56$ & 10.874 & 0.028 \\
Job & Civil Service, Private enterprise employees, & 10.213 & 0.037 \\
type & Self-employed, Unemployed, Student & & \\
\hline
\end{tabular}

preferred their children to be in the medical industry is shown in Fig. 6. Several factors, such as job title, education, perception of medical staff's income, and what MPs prioritized to improve in routine medical work, were statistically significant for the MPs to choose whether they wanted their children to be in the medical industry $(p<$ 0.05); the data are shown in Table 7. Age, job type, cognition of medical staff's income level, perception differences in the DPR were statistically significant factors for the GP to choose whether they wanted their children to be in the medical industry $(\mathrm{p}<0.05)$; the data are given in Table 8. Among the $154 \mathrm{MPs}$, the most wanted to improve their salary (40.26\%), followed by safety issues (17.53\%); the improvement of the working environment was the least preferred factor (3.25\%), as shown in Fig. 7.

\section{Discussion}

Economic development and an increase in the aging population have heightened the demand for medical resources [16]. While China is in a period of rapid economic development, her large population, the polarization of the rich and the poor, the increase in the aging population, and the uneven distribution of medical resources have created complex problems in China's medical industry $[17,18]$. Rational allocation of medical resources and finding ways to improve treatment efficiency are two of the most pressing issues right now. Finding a way to increase the DPR, in this context, can play an important role in reforming China's health care system. Since the medical industry closely related to people's wellbeing, improved DPR would be mutually beneficial to both the doctors and the patients. For example, improved DPR can improve treatment efficacy and better medical experience to the patients, while it will provide the doctors with better working environments and increase work efficiency. Although the 


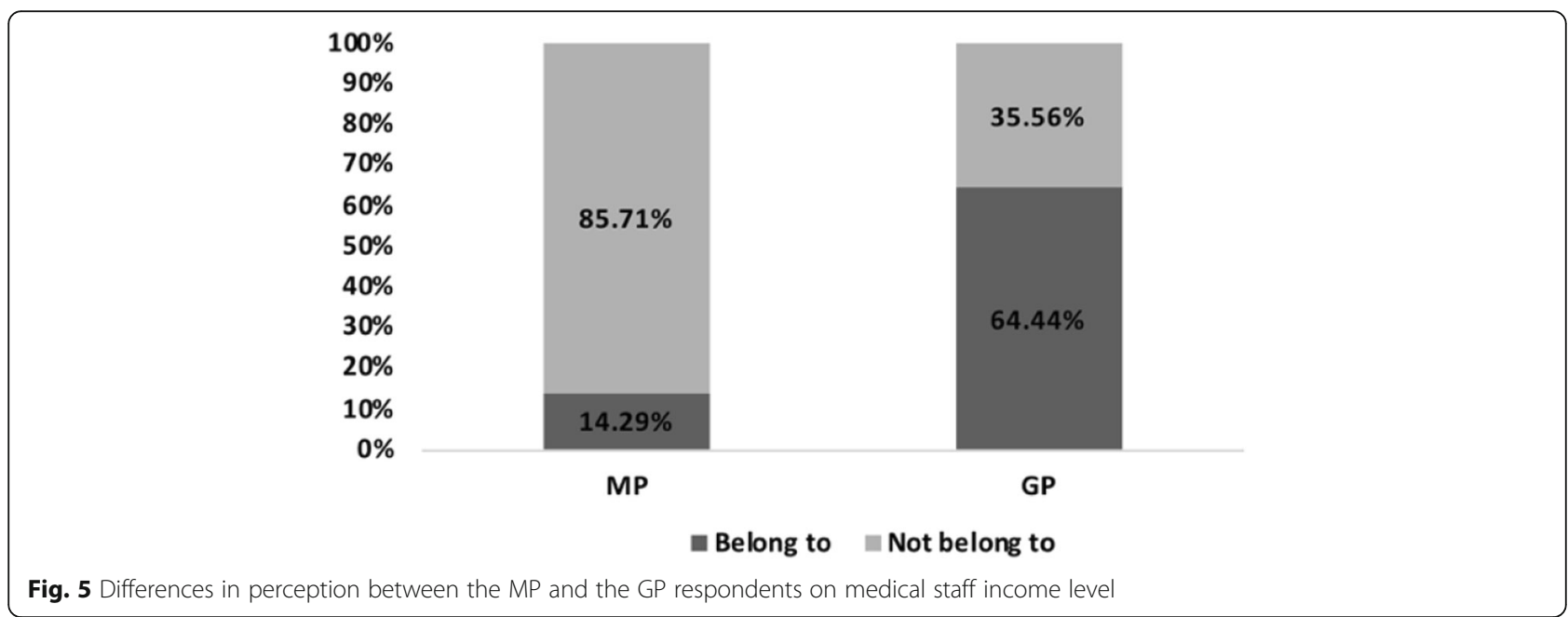

Chinese government has taken many measures to improve the DPR, success has been minimal. Our data on $\mathrm{MP}$ and GP respondents' perception of the DPR showed that only $11.04 \%$ of the MPs and $14.89 \%$ of the GPs believed that the current DPR is harmonious. This indicates that the DPR is at a relatively tense level in China, which is consistent with previous research [10]. However, there was a significant difference in the perception of the nature of medical services and the income of the people employed in the medical industry between the two groups.

\section{Analysis of the status of the DPR between the MP and the GP and the difference in perception about medical service}

The service industry is considered to be service-oriented, such as restaurant waiters and salespeople. Whether the medical industry is regarded as service-oriented or business oriented, it has an impression of patients' expectations of MP, and in turn affects DPR. A significant percentage of the participants, $97.4 \%$ of the MP and $95.74 \%$ of the GP respondents, believed that the service attitude of medical staff was as important as the MPs' professional skills. Moreover, $54.55 \%$ of the MPs believed that the medical industry was a service industry, and $71.12 \%$ of the GPs believed that the medical industry was a service industry. These data showed that while the MP and the GP had a similar understanding of the importance of service attitude in the medical industry, the two groups' opinions differed when it came to the nature of the service of the medical industry. The GP group tended to think that the medical industry was service-oriented, while the MP group thought the opposite was true. This may lead to differences in the expectations and communication methods between doctors and patients during medical treatment, which exacerbates

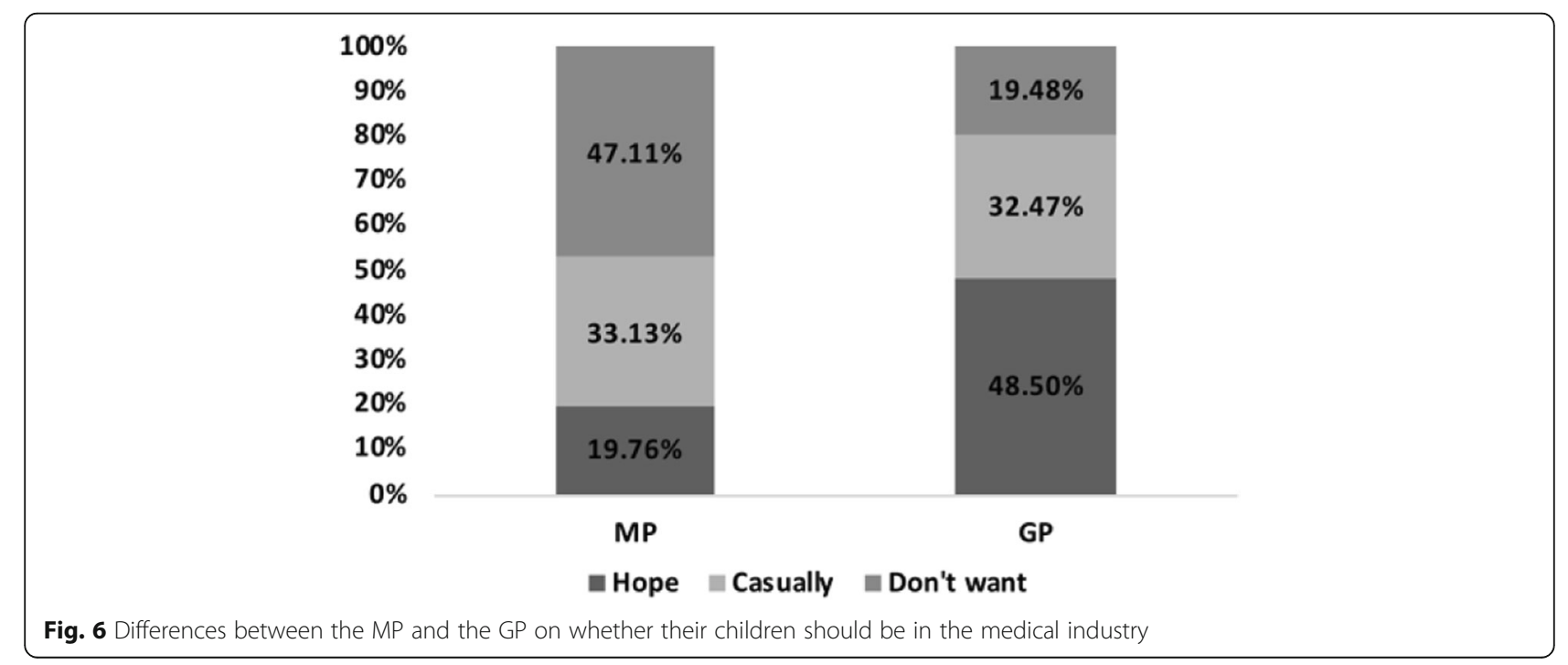


Table 7 Differences affecting MP's choice of whether their children are engaged in the medical industry

\begin{tabular}{|c|c|c|c|}
\hline Group & & $x^{2}$ & $\mathbf{P}$ \\
\hline Job title & $\begin{array}{l}\text { Primary, Intermediate, } \\
\text { Deputy Senior, Advanced }\end{array}$ & 13.032 & 0.043 \\
\hline Education & $\begin{array}{l}\text { Elementary school and } \\
\text { below, Junior and high } \\
\text { school, Technical secondary } \\
\text { school/college, } \\
\text { Undergraduate, } \\
\text { Postgraduate and above }\end{array}$ & 13.301 & 0.038 \\
\hline $\begin{array}{l}\text { Whether medical staff } \\
\text { belong to high-income } \\
\text { groups. }\end{array}$ & Belong to/not belong to & 12.318 & 0.002 \\
\hline $\begin{array}{l}\text { MP's choice of what they } \\
\text { want to improve in } \\
\text { routine medical work. }\end{array}$ & $\begin{array}{l}\text { Social status, Salary, Safety, } \\
\text { Work time, Night shift } \\
\text { frequency, Cumbersome } \\
\text { hospital assessment, Doctor- } \\
\text { patient relationship, } \\
\text { Working environment }\end{array}$ & 34.86 & 0.002 \\
\hline
\end{tabular}

the DPR crisis [19]. A comparison of the service attitude between medical staff with government staff showed that $26.06 \%$ of the GPs thought that medical staff offered better service, and only $6.06 \%$ thought that the government staff offered better service. Compared with traditional service industries, $17.58 \%$ of the GPs thought that medical staff offered service, and $41.25 \%$ thought that the reverse was true. This indicated that the service attitude of medical staff between that of government staff and staff of traditional service industries is significantly better than the non-traditional service industry. This suggested that to a certain extent, the service attitude of medical staff is not directly responsible for the tension in the DPR.

\section{Analysis of the difference between MP and GP respondents' general perception of the medical industry} Our data show that $85.71 \%$ of the MPs thought that they did not earn high salaries while $14.29 \%$ thought they did. Among the GP respondents, 35.56\% thought that MP did not earn high salaries while 212 (64.44\%) thought they did. These data showed that there was a difference

Table 8 Differences affecting the GP's choice of whether their children should be in the medical industry

\begin{tabular}{|c|c|c|c|}
\hline Group & & $x^{2}$ & $\mathbf{P}$ \\
\hline Age & $\leq 25 / 26-35 / 36-45 / 46-55 / \geq 56$ & 19.371 & 0.013 \\
\hline Job type & $\begin{array}{l}\text { Institution/Civil Service, Private } \\
\text { enterprise employees, Self- } \\
\text { employed, Unemployed, } \\
\text { Student }\end{array}$ & 25.104 & 0.001 \\
\hline $\begin{array}{l}\text { Whether medical staff } \\
\text { belong to high-income } \\
\text { groups. }\end{array}$ & Belong to/not belong to & 9.949 & 0.007 \\
\hline Current status of DPR. & Harmony /Normal/Tense & 13.869 & 0.008 \\
\hline
\end{tabular}

in perception on MPs' income between the MP and the GPs: the majority of the GP thought the MPs' income was high while the reverse was true for the MP. While $47.11 \%$ of the GPs wanted their children to be in the medical profession, only $19.48 \%$ of the MPs wanted that. Age, job type, cognition of medical staff's income level, and the status quo of doctor-patient relationship differences had an impact on whether GP wanted their children to choose the medical profession. Interestingly, the recognition of the current status of the doctor-patient relationship did not affect GP's choice in this regard. Among the GP who wanted their children to be in the medical industry, $83.84 \%$ thought the DPR was currently tense, and only $14.89 \%$ thought the DPR was harmonious. Our data on the MPs' preferred aspect to improve the routine medical works showed that majority of the MPs hoped to improve their salaries (40.26\%), followed by safety (17.53\%) and social status (12.99\%); only $8.44 \%$ wanted to improve the DPR. Our data was consistent with the results of another study [20]. These results suggested that the GPs' perception of the medical industry does not change with either tense or harmonious DPR. The factors medical practitioners need to improve most are related to personal life, such as salary, safety, and social status. The problems in the DPR is one of the common problems of both developed and developing countries [21], which has also intensified in China. The general public believes this happens because the patients do not understand the medical staff's instructions and do not pay attention to the instructions. Thus, the media always tends to portray doctors and nurses as heroes. Headlines such as "Sick doctor goes to work", "Writing medical orders while dripping", "Working continuously for 48 hours during the Spring Festival" encourages doctors to sacrifice themselves for patients [13, 22]. Continuously raising the moral standards of the medical industry and raising the professional positioning of the medical industry while ignoring the needs of medical personnel as ordinary people will inevitably increase their professional burden as patients will have unreasonable expectations from the medical staff. Studies have shown that violent medical injuries mostly occur in areas where high-quality medical resources are concentrated, such as top hospitals, and this mostly happens because patients expect too much from the doctors [11, 23]. Whether the MP and the GP respondents' different perceptions about the nature of services in the medical industry is related to high demands and ethical standards set by public opinion needs to be investigated in the future.

\section{Conclusions}

This study indicated that the MP's and the GP's perception of the current status of DPR, the importance of 

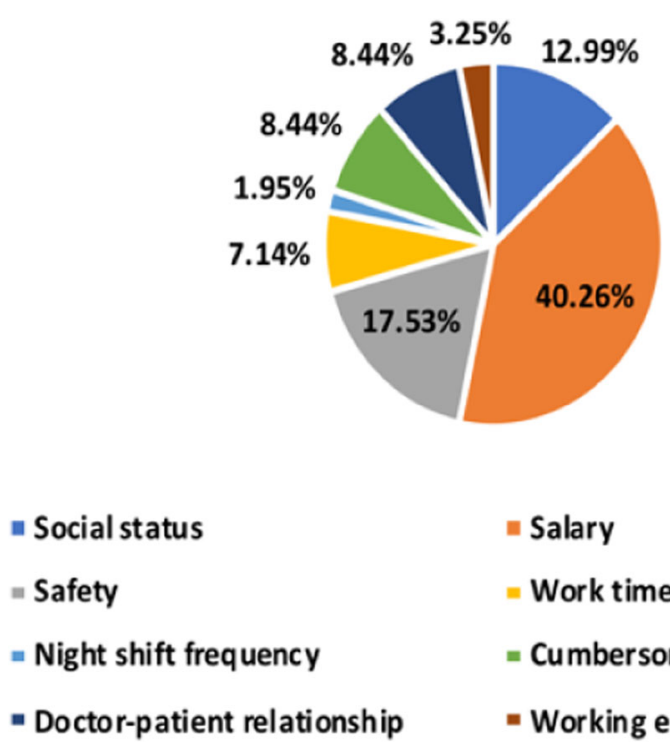

" Salary

$=$ Work time

= Cumbersome hospital assessment

= Working environment

Fig. $7 \mathrm{MP}^{\prime} \mathrm{s}$ choice of what they want to improve in routine medical work

medical service attitudes, and the general sense of the medical industry are similar. Both groups believed that DPR is currently tense and affirmed the importance of service attitude in the medical industry. Their main difference lies in the perception of the nature of medical services and the income of the medical industry. Unlike the MPs, the GPs believed that the medical industry belongs to the service industry and that medical personnel belonged to the high-income group. The solution to the DPR crisis lies in addressing the problem from both the medical professionals' and patients' perspectives, finding the key discrepancies, and implementing measures to minimize those discrepancies. Balancing the expectations of patients in the medical industry and increasing public awareness of the real situation in the medical industry may be a feasible way to improve the DPR.

\section{Limitations and suggestions for future research}

We surveyed MP and GP from Jiangsu and Henan provinces. The sample size of this study is not large enough. This makes our research might not represent the whole situation in China and unable to fully reflect the views of people from rural areas on the DPR. In our future research, we will expand the scope of the survey in order to more comprehensively reflect the views on DPR of Chinese people, and the difference between people's demand for medical services in developed and underdeveloped regions.

\section{Authors' contributions}

STQ and ZHL contributed equally to the manuscript. ZHG designed the research. STQ and $\mathrm{LMH}$ contributed analytic tools, ZHL, SHB and LWT collected and processed the data. STQ, ZHG and CHB critically reviewed the manuscript and assisted in the final write-up of the manuscript. All authors read and approved the final manuscript.

\section{Funding}

1. National Natural Science Foundation of China (81973737);

2. A Project Funded by the Priority Academic Program Development of Jiangsu Higher Education Institutions (PAPD);

3. The Open Projects of the Discipline of Chinese Medicine of Nanjing University of Chinese Medicine Supported by the Subject of Academic priority discipline of Jiangsu Higher Education Institutions (ZYX03JG002; ZYX03KF003).

This study was funded by the National Natural Science Foundation of China (1) and Nanjing University of Chinese Medicine $(2,3)$. The funding body paid for this research to those who participated in the questionnaire survey, and provided statistical analysis software and technical support. The funding body had input to the collection, analysis, and interpretation of data, but no role in the design of the study and in writing the manuscript.

\section{Availability of data and materials}

All data supporting the study is presented in the manuscript or available upon request from the corresponding author of this manuscript

(Hongguang Zhou) at Email: 260105@njucm.edu.cn

\section{Ethics approval and consent to participate}

All aspects of the study protocol, was authorized by the Institutional Review Board at Nanjing University of Traditional Chinese Medicine before the initiation of this study. All participants were allowed at least 15 min to complete the questionnaire. They read the consent form attached to the paper questionnaire and provided informed consent prior to answering any questions.

\section{Consent for publication}

The authors of this study declare that they have no objections to the publication of this article. The individual person's data in any form (including any individual details, images or videos) in this manuscript, all consent for publication from that person, or in the case of children, their parent or legal guardian. 


\section{Competing interests}

The authors declare that they have no competing interest.

\section{Author details}

'Institute of Oncology, The First Clinical Medical College, Nanjing University of Chinese Medicine, Nanjing 210046, Jiangsu Province, China. 'Liaoning University of Chinese Medicine, Shenyang 110847, Liaoning Province, China. ${ }^{3}$ Wuxi Xishan Hospital of Traditional Chinese Medicine, Wuxi 214000, Jiangsu Province, China. ${ }^{4}$ Science and Technology Department, Jiangsu Collaborative Innovation Center of Traditional Chinese Medicine Prevention and Treatment of Tumor, Nanjing University of Chinese Medicine, Nanjing 210046, Jiangsu Province, China. ${ }^{5}$ Department of Oncology, Affiliated Hospital of Nanjing University of Chinese Medicine, Nanjing 210029, Jiangsu Province, China.

Received: 15 July 2020 Accepted: 29 September 2020

Published online: 15 October 2020

\section{References}

1. Shrivastava SR, Shrivastava PS, Ramasamy J. Exploring the dimensions of doctor-patient relationship in clinical practice in hospital settings. Int Health Policy Manag. 2014;2(4):159-60.

2. Kaba R, Sooriakumaran P. The evolution of the doctor-patient relationship. Int J Surg. 2007;5(1):57-65.

3. Ortega-Lenis D, Mendez F. Survey on health, well-being and aging. SABE Colombia 2015: Technical report. Colomb Med (Cali). 2019;50(2):128-38.

4. Wang L, Wang Z, Ma Q, et al. The development and reform of public health in China from 1949 to 2019. Glob Health. 2019;15(1):45.

5. Shi L. Health care in China: a rural-urban comparison after the socioeconomic reforms. Bull World Health Organ. 1993;71(6):723-36.

6. Duan J, Jiao F, Zhang Q, et al. Predicting Urban Medical Services Demand in China: An Improved Grey Markov Chain Model by Taylor Approximation. Int J Environ Res Public Health. 2017;14(8):883.

7. Namazi H, Aramesh K, Larijani B. The doctor-patient relationship: toward a conceptual re-examination. J Med Ethics Hist Med. 2016;9:10.

8. de Waard CS, Poot AJ, den Elzen WPJ, et al. Perceived doctor-patient relationship and satisfaction with general practitioner care in older persons in residential homes. Scand J Prim Health Care. 2018;36(2):189-97.

9. Chen J, Zhou MY, Liu QY, et al. High time for ease the doctor-patient relationship in China. J Forensic Legal Med. 2020;72:101961.

10. He AJ. The doctor-patient relationship, defensive medicine and overprescription in Chinese public hospitals: evidence from a cross-sectional survey in Shenzhen city. Soc Sci Med. 2014;123:64-71.

11. Peng W, Ding G, Tang Q, et al. Continuing violence against medical personnel in China: a flagrant violation of Chinese law. Biosci Trends. 2016; 10(3):240-3.

12. Du Y, Wang W, Washburn DJ, et al. Violence against healthcare workers and other serious responses to medical disputes in China: surveys of patients at 12 public hospitals. BMC Health Serv Res. 2020;20(1):253.

13. Sun J, Liu S, Liu Q, et al. Impact of adverse media reporting on public perceptions of the doctor-patient relationship in China: an analysis with propensity score matching method. BMJ Open. 2018;8(8):e022455.

14. Zhou C, Mou H, Xu W, et al. Study on factors inducing workplace violence in Chinese hospitals based on the broken window theory: a cross-sectional study. BMJ Open. 2017;7(7):e016290

15. Wu D, Wang Y, Lam KF, et al. Health system reforms, violence against doctors and job satisfaction in the medical profession: a cross-sectional survey in Zhejiang Province, Eastern China. BMJ Open. 2014;4(12):e006431.

16. Orentlicher D. Healthcare, health, and income. J Law Med Ethics. 2018;46(3): 567-72.

17. Liu Y. China's public health-care system: facing the challenges. Bull World Health Organ. 2004;82(7):532-8

18. Ma J, Lu M, Quan H. From a national, centrally planned health system to a system based on the market: lessons from China. Health Aff (Millwood). 2008;27(4):937-48.

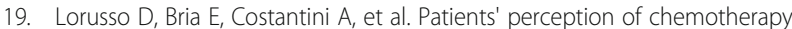
side effects: Expectations, doctor-patient communication and impact on quality of life - An Italian survey. Eur J Cancer Care (Engl). 2017;26(2):e12618.

20. Gong Y, Han T, Chen W, et al. Prevalence of anxiety and depressive symptoms and related risk factors among physicians in China: a crosssectional study. PLoS One. 2014;9(7):e103242.
21. Hacer TY, Ali A. Burnout in physicians who are exposed to workplace violence. J Forensic Legal Med. 2020;69:101874.

22. Tucker JD, Cheng Y, Wong B, et al. Patient-physician mistrust and violence against physicians in Guangdong Province, China: a qualitative study. BMJ Open. 2015;5(10):e008221.

23. Moore P, Vargas A, Núñez S, et al. A study of hospital complaints and the role of the doctor-patient communication. Rev Med Chil. 2011;139(7):880-5.

\section{Publisher's Note}

Springer Nature remains neutral with regard to jurisdictional claims in published maps and institutional affiliations.
Ready to submit your research? Choose BMC and benefit from:

- fast, convenient online submission

- thorough peer review by experienced researchers in your field

- rapid publication on acceptance

- support for research data, including large and complex data types

- gold Open Access which fosters wider collaboration and increased citations

- maximum visibility for your research: over $100 \mathrm{M}$ website views per year

At $\mathrm{BMC}$, research is always in progress.

Learn more biomedcentral.com/submissions 